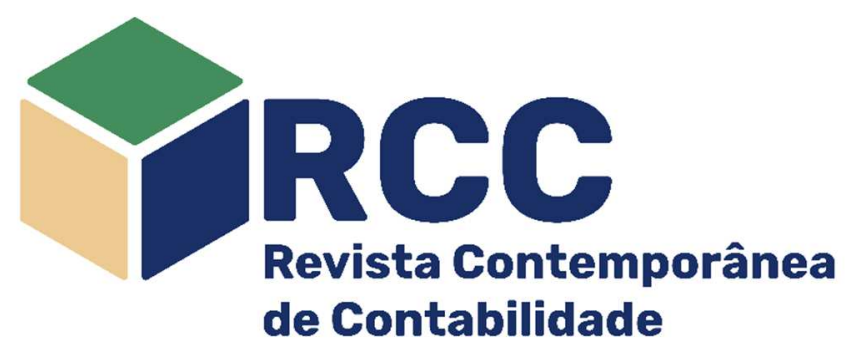

\title{
Quem está ficando para trás? Uma análise da transparência pública dos portais eletrônicos de municípios tocantinenses
}

\author{
Who is falling behind? An analysis of the public transparency of electronic portals in the municipalities \\ of Tocantins
}

\section{¿Quién se está quedando atrás? Un análisis de la transparencia pública de los portales electrónicos de los municipios de Tocantins}

\author{
Xenise Milhomem Brandão Araújo \\ Mestre em Ciências Contábeis (UNISINOS) \\ Assistente em Administração (UFT), Palmas/TO, Brasil \\ xenise@mail.uft.edu.br \\ https://orcid.org/0000-0003-2967-1863
}

José Ribamar Marques de Carvalho* Doutor em Recursos Naturais (UFCG)

Professor do Mestrado Profissional em Administração Pública e dos

Cursos de Graduação em Administração e Ciências Contábeis (UFCG), Sousa/PB, Brasil ribamar.ccjs@ufcg.edu.br

https://orcid.org/0000-0003-3482-9231
Clóvis Antônio Kronbauer Doutor em Contabilidade e Auditoria na Universidade de Sevilla - Espanha Professor do PPG em Ciências Contábeis (UNISINOS), São Leopoldo/RS, Brasil clovisk@unisinos.br https://orcid.org/0000-0002-1454-9243

\author{
Gianinni Martins Pereira Cirne \\ Doutoranda em Ciências Contábeis (UNISINOS) \\ Professora Adjunta I do Curso de Ciências Contábeis (UFCG) \\ João Pessoa/PB, Brasil \\ gianinni.martins@gmail.com \\ https://orcid.org/0000-0002-9355-2749 (0)
}

Endereço do contato principal para correspondência* Rua Sinfrônio Nazaré, 38, Centro, CEP: 58.800-590, Sousa/PB, Brasil

\section{Resumo}

Esta pesquisa visou analisar o nível de transparência pública das informações sobre os atos da gestão pública divulgadas nos sítios eletrônicos de prefeituras de municípios dos estados de Tocantins. Quanto à metodologia, classifica-se como descritiva, documental e quali-quantitativa. Assim, foram acessados os sites oficiais de 66 prefeituras tocantinenses, analisados por faixa populacional, conforme modelos propostos por Silva (2013), Amorim (2012) e Amorim e Almada (2016). Os resultados encontrados, de modo geral, revelam que a observância à LAI, em média, foi melhor do que à LRF. No tocante à acessibilidade dos sites oficiais das prefeituras que fazem parte da amostra, observou-se que apresentam uma transparência pública razoável nos aspectos quanto ao acesso por portadores de necessidades especiais e à flexibilidade e eficiência do portal. Percebeu-se também que a usabilidade e acessibilidade e acessibilidade tem sido adotadas pelos portais, todavia ainda necessitam de maior empenho no sentido de atender plenamente aos aspectos obrigatórios e voluntários dispostos nos dispositivos legais.

Palavras-chave: Lei de Responsabilidade Fiscal; Lei de Acesso à Informação; Usabilidade; Acessibilidade

\section{Abstract}

This research aimed to analyze the level of public transparency of information about the acts of public management published on the websites of city halls of municipalities in the states of Tocantins. As for the methodology, it is classified as descriptive, documentary and quali-quantitative. Thus, the official websites of 66 Tocantins city halls were accessed, analyzed by population range, according to models proposed by Silva (2013), Amorim (2012) and Amorim and Almada (2016). The results found, in general, reveal that compliance with LAI, on average, was better than with LRF. Regarding the accessibility of the official websites of the municipalities that are part of the sample, it was observed that they present reasonable public transparency in terms of access by people with special needs and the flexibility and efficiency of the portal. It was also noticed that the usability and accessibility and accessibility have been adopted by the portals, however they still need greater effort in order to fully meet the mandatory and voluntary aspects provided for in the legal provisions. Keywords: Fiscal Responsibility Law; Access to Information Law; Usability; Accessibility 


\section{Resumen}

Esta investigación tuvo como objetivo analizar el nivel de transparencia pública de la información sobre los actos de gestión pública publicados en los sitios web de los ayuntamientos de los municipios de los estados de Tocantins. En cuanto a la metodología, se clasifica como descriptiva, documental y cuali-cuantitativa. Así, se accedió a los sitios web oficiales de 66 prefecturas en Tocantins, analizados por población, según los modelos propuestos por Silva (2013), Amorim (2012) y Amorim y Almada (2016). Los resultados encontrados, en general, revelan que el cumplimiento de LAI, en promedio, fue mejor que con LRF. En cuanto a la accesibilidad de los sitios web oficiales de los municipios que forman parte de la muestra, se observó que presentan una transparencia pública razonable en términos de acceso por parte de personas con necesidades especiales y la flexibilidad y eficiencia del portal. También se observó que los portales han adoptado la usabilidad y la accesibilidad y la accesibilidad, sin embargo, todavía necesitan mayores esfuerzos para cumplir plenamente con los aspectos obligatorios y voluntarios previstos en las disposiciones legales.

Palabras clave: Ley de Responsabilidad Fiscal; Ley de Acceso a la Información; Usabilidad; Accesibilidad

\section{Introdução}

A legislação brasileira reconhece que o acesso a informação pública é um direito da sociedade e que - Estado deve implementar políticas públicas em conformidade com as exigências da sociedade, a transparência deve ser um dos elementos estruturais da capacidade técnica, financeira e gerencial do Estado. A capacidade do Estado em formular e implementar políticas públicas está relacionada à governança, o que exige práticas de gestão pública pautadas em aspectos como a prestação de contas e a transparência, que são alguns dos princípios da governança pública (SECCHI, 2009; OLIVEIRA; PISA, 2015). Todavia, Tagesson, Klugman e Ekström (2013) destacam que não basta o Estado simplesmente divulgar os atos da gestão pública para se eximir de penalizações legais, é importante observar a forma como essas informações estão sendo disponibilizadas, quais são as informações e a qualidade delas, se são úteis e compreensíveis às partes interessadas.

As mudanças estruturais ocorridas no mundo como consequências da interferência das novas tecnologias da comunicação e da rápida disseminação das informações têm contribuído para a atuação dos segmentos sociais, público ou privado no processo de melhoria da prestação de contas na utilização dos recursos públicos e garantia da permanência dos direitos e deveres dos cidadãos. Esse cenário de transformações e a promulgação das Leis Complementares n. 101/2000, n. 131/2009, Lei n. 12.527/2011 e Lei Complementar no 156/2016, tem influenciado positivamente os gestores públicos e as partes interessadas na mudança de postura perante as atividades de interesse público na busca por melhores formas de fiscalizar e prestar contas de suas atividades.

Várias pesquisas nacionais foram realizadas em torno da temática desse estudo, desde a esfera nacional até a municipal (PLATT NETO et al., 2007; BERNARDES, SANTOS; ROVER, 2012; JAHNS; RAUPP, 2016; CALVOSA; SILVA; KRAKAUER, 2017; TAVARES; CERQUINHO; PAULA, 2018). Iniciativas internacionais também tem sido foco de estudos (PAPENFUB; SCHAEFER, 2010; HILGERS; PILLER, 2011; WELCH, 2012; ANDREEVA; ANSELL; HARRISON, 2014; STAROSCKY et al., 2015; ROGOSIC; PALOS, 2017; RíOS et al. 2018), evidenciando que ainda existem muitas limitações e aspectos a serem investigados em relação a temática da transparência pública.

Dentre as Unidades Federativas Brasileiras o Tocantins é o estado mais novo, tendo sido criado em 1988, ocupando até o referido ano a região Norte do estado de Goiás. O discurso autonomista de separação dessas regiões pregava a viabilidade da autonomia econômica, jurídica e político-administrativa do Norte de Goiás, culminando na emancipação dessa região em 1988, formando o estado de Tocantins (CAVALCANTE, 2003). Examinar a transparência compulsória e voluntária de municípios de dois estados brasileiros que outrora formavam uma única unidade federativa permite apontar se novos estados geram melhor transparência pública.

Nesse sentido, a justificativa do estudo em pesquisar os municípios desse estado esteve centrada em identificar indícios se a transparência compulsória e voluntária poderia apresentar maior e melhor nível de transparência pública, já que parte-se do pressuposto que a gestão do estado apresentaria menores "vícios de gestão" e supostamente estaria mais inclinado a atender aos requisitos previstos nos dispositivos legais da Lei de Responsabilidade Fiscal (LRF) e da Lei de Aceso a Informação (LAI). Assim, diante do contexto apresentado, o presente estudo buscou responder ao seguinte questionamento: Qual o nível de transparência pública das informações sobre os atos da gestão divulgados nos sítios eletrônicos de prefeituras de municípios tocantinenses.

No intuito de responder a problemática objetivou analisar o nível de transparência pública das informações sobre os atos da gestão divulgados nos sítios eletrônicos de prefeituras de municípios tocantinenses. Vale salientar que a transparência funciona para alguns objetivos sob certas circunstâncias, mas não em outras. Portanto, ao invés de questionar o valor da transparência, faz mais sentido concentre-se em avaliar onde e como funciona (CUCCINIELLO; PORUMBESCU; GRIMMELIKHUIJSEN, 2017). 


\section{Revisão de Literatura}

\subsection{Governança aplicada ao Setor Público}

A governança tem um alcance amplo, indo além da gestão, engloba como uma organização é gerida, sua estrutura, seus membros (internos e externos), cultura, políticas e estratégia. Não há um modelo único de governança, é necessário realizar as adaptações que atendam à natureza e complexidade de cada ente. (BARRETT, 2002). Incialmente era aplicada apenas no setor privado, porém, atualmente tem sido ajustada para implementação no setor público. Trata-se da Governança Pública, um instrumento do controle social.

Para uma melhor governança pública é vital que haja integração e equilíbrio entre seus elementos, que conforme Barrett (2002) são: estrutura da gestão, planejamento, informações de desempenho, gerenciamento de riscos, conformidade e controle, auditoria e valores e código de ética. Estes elementos estão inter-relacionados, devendo ser combinados de forma adequada para alcançar uma melhor governança, o que exige compromisso da parte dos envolvidos.

A governança aplicada ao setor público não pode ser definida tão somente como a transposição de práticas de administração privada, já que as particularidades do setor público impedem a implementação exata das práticas de organizações privadas. Ela se refere à capacidade do Estado e envolve a convivência harmônica com os diferentes grupos sociais e atores políticos, sejam da sociedade civil ou internos ao próprio Estado, bem como as normas e regras que regem a representação desses atores e a gestão do aparelho estatal (RONCONI, 2001; SILVA; MARTINS; CKAGNAZAROFF, 2013).

Para melhorar o relacionamento entre o agente e o principal, as práticas de governança devem ser fundamentadas em princípios. Destacam-se a transparência, a equidade, a prestação de contas e a responsabilidade, similares aos princípios básicos de governança corporativa estabelecidos pelo Instituto Brasileiro de Governança Corporativa, que são descritos por diversos autores conforme apresentado no Quadro 1.

\begin{tabular}{|c|c|c|}
\hline Princípio & Descrição & Autor / Ano \\
\hline Transparência & $\begin{array}{l}\text { No setor público a informação deve ser encarada como um recurso } \\
\text { público, tampouco sendo propriedade de uma entidade particular. À } \\
\text { medida que a administração pública é transparente, evidenciando } \\
\text { amplamente as ações tomadas pela gestão, reduz a assimetria } \\
\text { informacional entre a sociedade e o Estado e permite o controle por } \\
\text { parte dos órgãos competentes e também pela sociedade. }\end{array}$ & $\begin{array}{l}\text { BAIRRAL; SILVA; } \\
\text { ALVES (2015) }\end{array}$ \\
\hline Equidade & $\begin{array}{l}\text { Para que as ações e as políticas implementadas pelos gestores } \\
\text { públicos promovam a equidade (tratamento justo e isonômico) entre os } \\
\text { cidadãos, é necessário garantir as condições para que todos tenham } \\
\text { acesso ao exercício de seus direitos civis - liberdade de expressão, de } \\
\text { acesso a informação, de associação, de voto, igualdade entre gêneros } \\
\text {-, políticos e sociais - saúde, educação, moradia, segurança. }\end{array}$ & BRASIL (2014) \\
\hline $\begin{array}{l}\text { Prestação de } \\
\text { contas } \\
\text { (accountability) }\end{array}$ & $\begin{array}{l}\text { Sendo que os administradores do Estado foram eleitos pela sociedade } \\
\text { para gerenciar os recursos públicos, é necessário que haja uma } \\
\text { prestação de contas (voluntária ou compulsória) de modo que a } \\
\text { sociedade possa conhecer e avaliar como os gestores estão } \\
\text { desempenhando seu papel. Essa fiscalização pode ser facilitada ou } \\
\text { dificultada de acordo com as informações disponibilizadas, onde, } \\
\text { quando e como são publicadas. }\end{array}$ & $\begin{array}{c}\text { ANDREEVA; } \\
\text { ANSELL; } \\
\text { HARRISON (2014) }\end{array}$ \\
\hline Responsabilidade & $\begin{array}{l}\text { Os gestores públicos devem atuar pensando não apenas nos } \\
\text { resultados de suas ações no curto prazo, mas também no longo prazo, } \\
\text { pois as consequências dos atos de um gestor podem ir além do término } \\
\text { do seu mandato. É necessário ter em mente a longevidade da } \\
\text { administração pública e englobar aspectos sociais e ambientais. Dessa } \\
\text { forma, a responsabilidade do Estado para com a sociedade vai além } \\
\text { de uma simples prestação de serviço. }\end{array}$ & $\begin{array}{c}\text { BRASIL (2014); } \\
\text { LAZZINI; ZARONE } \\
(2012)\end{array}$ \\
\hline
\end{tabular}

Fonte: Elaborado com base nos autores citados.

As práticas de governança no setor público, na visão de Bogoni et al. (2010), melhoram o desempenho, possibilitando uma prestação de serviços com qualidade e custo mais baixo, e o torna mais confiável. Isso só é possível porque essas práticas são baseadas em princípios que permitem a gestão pública atuar com responsabilidade, promovendo a equidade, prestando conta de seus atos e sendo transparente por evidenciar como tem gerenciado os recursos públicos.

\subsection{Transparência no Setor Público}

A transparência é um dos principais fundamentos de um Estado democrático, além de um atributo que contribui para a percepção de uma boa gestão pública. Por pressuposto, quanto mais transparente um 
governo de mostra, mais responsável e responsivo ele se assume. Logo, se torna mais aberto a avaliações críticas, sugestões e controles da sociedade. Dessa maneira, o tema de transparência pública está relacionado a uma série de outras discussões na área da administração pública (SANTOS; MOTA, 2020).

Entende-se que os gestores do recurso público devem divulgar informações de modo a prestar contas sobre sua atuação. Essa evidenciação (disclosure), seja voluntária ou compulsória, pode ocorrer através de portais eletrônicos, permitindo a fiscalização tanto pelos órgãos competentes como pela sociedade (BAIRRAL; SILVA; ALVES, 2015). Marques (2014) complementa que ao longo dos anos a gestão pública vem desenvolvendo mecanismos visando às boas práticas de governança, sendo a transparência a ferramenta mais utilizada e exigida pela sociedade e por lei. Observa-se com isso, que a transparência pública pode minimizar as questões que permeiam à má gestão do recurso público por ser capaz de favorecer a participação da sociedade nas decisões governamentais via conhecimento das informações publicadas sobre os atos da administração pública.

No Brasil uma das ferramentas de transparência na gestão pública é a LC № 101/2000, denominada Lei de Responsabilidade Fiscal, que concebe normas de finanças públicas voltadas para a responsabilidade na gestão fiscal. Um dos pontos significativos da LRF é o pressuposto de uma ação planejada e transparente para que haja responsabilidade na gestão fiscal, seja na União, nos Estados, no Distrito Federal ou nos Municípios. (BRASIL, 2000).

Marengo e Diehl (2011) também destacam que a LRF exige novos padrões de controle e transparência dos atos dos gestores públicos, pressupondo ações planejadas e transparentes por meio do cumprimento de metas que deverão ser constantemente mensuradas. Rausch e Soares (2010, p.42) afirmam que a LRF é uma conquista para o controle das contas públicas.

Outra forte fonte transparência, foi implementada com a Lei no 12.527/2011, intitulada Lei de Acesso à Informação (LAI), dispõe sobre os procedimentos a serem observados pela União, Estados, Distrito Federal e Municípios, com o intuito de garantir o acesso a informações públicas. Estas informações podem ser divulgadas em qualquer meio ou instrumento legítimo de publicidade que a administração pública dispuser, mas é indispensável à publicidade nos sítios eletrônicos, exceto aos municípios com população de até 10.000 habitantes.

A transparência pública oportuniza o controle social por facilitar o monitoramento dos atos realizados pelos gestores CRUZ et al 2012; AVELINO;ANGOTTI; COLAUTO, 2012) de modo que a população possa acompanhar as prestações de contas, fiscalizar e cobrar uma melhor aplicação dos recursos (MENESES, 2011). "A importância de exercer o controle social está em tratar-se de recursos públicos. É direito de qualquer cidadão entender e controlar a vinculação e a aplicação desses valores [...]." (MARENGO; DIEHL, 2011, p.125).

De acordo com os estudos artigos nacionais desenvolvidos sobre o tema transparência observa-se uma maior concentração de estudos sobre transparência para atendimento à legislação, nas quais verificam a aderência dos municípios em relação a LRF (SILVA; SEGATTO; SILVA 2016; PIRES et al. 2013; BEUREN; SÖTHE 2009; GOMES 2015; MARQUES 2014). Alguns autores pesquisaram verificar o nível de transparência das informações acerca da gestão pública divulgadas nos portais eletrônicos (CRUZ et al., 2012; CRUZ; SILVA; SANTOS 2009; AMORIM 2012; PAULA 2010; JAHNS; RAUPP, 2016).

Assim, quando o gestor público adota uma postura de governo transparente e alinhada à melhoria dos mecanismos de controle social maior poderá ser o ganho no gerenciamento dos recursos públicos. Diversos são os meios de comunicação que a gestão pública pode utilizar para dar transparência aos seus atos. A divulgação desses atos em páginas oficiais na internet como um meio acessível à população, permite que o cidadão acompanhe a gestão pública, analise os procedimentos de seus representantes e favoreça 0 crescimento da cidadania, trazendo às claras informações anteriormente veladas nos prédios públicos (FIGUEIREDO; GAZONI, 2016).

Platt Neto et al. (2007) sugerem que para avaliar a transparência pública formado é necessário considerar três dimensões: 1) publicidade que está subdividida em divulgação e acesso; 2) compreensibilidade que se compõe pela linguagem e apresentação das informações públicas; e 3) utilidade para decisões: relevância, comparabilidade e confiabilidade.

Segundo esses autores para que haja transparência, deve haver publicidade das informações, ou seja, divulgação em meios de baixo custo e de alcance ao maior número possível de pessoas; compreensibilidade das informações, expressa a necessidade de fomentar o entendimento através da apresentação visual e de uma linguagem simples; e as informações devem ser úteis, relevantes, confiáveis e passíveis de comparabilidade com outros períodos ou outras entidades. Outrossim, as informações devem ser oportunas, providas com tempestividade e em tempo hábil, devendo haver um equilíbrio para que não haja escassez nem excesso de informações (PLATT NETO et al., 2007).

$\mathrm{Na}$ medida em que o acesso à internet se propaga, aumenta a demanda da sociedade por informações e serviços do Estado em meio eletrônico, possibilitando o aperfeiçoamento e melhoria na divulgação das informações de natureza pública. Chen e Neshkova (2020) argumentam que tanto acadêmicos quanto profissionais têm defendido o aumento da transparência da gestão pública como forma de melhorar o funcionamento do setor público, promover maior responsabilidade e combater a ameaça global de corrupção. 
Apesar das exigências mundiais de maior divulgação, as análises empíricas sobre se e como a transparência da gestão pública realmente afeta os resultados da governança ainda são limitadas.

No âmbito internacional também são encontradas várias iniciativas correlatas ao problema de pesquisa desse estudo, como é o caso por exemplo de Styles e Tennyson (2007) acerca da disponibilidade e acessibilidade dos relatórios financeiros do governo local na Internet para uma amostra de 300 municípios dos Estados Unidos da América, ou o estudo de Sol. (2013) e Rios et al. (2013) que identificaram os determinantes econômicos, sociais e institucionais da transparência do governo local na Espanha, ou o estudo de Gesuele e Matalo (2018) que identificaram esses mesmos determinantes na Espanha e Itália, ou ainda a representação política das mulheres nos conselhos locais espanhóis e sua influência no nível de transparência pública (SAEZ-MARTIN, CABA-PEREZ; LOPEZ-HERNANDEZ, 2017).

As evidências empíricas supracitadas reforçam o entendimento e a importância de analisar a transparência da gestão pública, uma vez que as constatações tem apontado que a maioria das entidades e governos locais, estaduais, nacionais e internacionais ainda não cumprem a legislação como deveriam e precisam aperfeiçoar as estratégias de divulgação das ações governamentais. Nesse sentido, o presente estudo procura suprir a lacuna e o gap existente dentro dessa temática, na tentativa de apontar a obediência ou não à legislação e identificar o nível em que as evidenciações obrigatórias e voluntárias que estão ocorrendo nos municípios tocantinenses.

\section{Procedimentos Metodológicos}

A pesquisa é classificada em descritiva quanto aos seus objetivos, pois nela são descritas as características da amostra em relação à transparência da gestão pública. Quanto aos procedimentos, é documental, pois os dados principais foram coletados nos sítios eletrônicos de municípios do estado de Tocantins. No que se refere à abordagem, é quali-quantitativa.

O Censo Demográfico do Instituto Brasileiro de Geografia e Estatística (IBGE) de 2010 identificou 139 municípios no estado de Tocantins. Para o estudo, a amostra foi composta por 66 municípios. O critério de escolha foi dispor de uma estimativa populacional a partir de 5.000 habitantes, conforme identificado no quadro2. Dos municípios tocantinenses que compõem a amostra, apenas 2 são de grande porte (acima de 100.000 habitantes), 1 de médio porte (50.001 a 100.000 habitantes) e 63 de pequeno porte (até 50.000 habitantes). Dessa amostra, 27 municípios estão obrigados a divulgar informações em seus sítios eletrônicos, e 39 estão dispensados pela LAI.

Quadro 2- Amostra do estado do Tocantins

\begin{tabular}{|c|c|l|}
\hline $\begin{array}{c}\text { Faixa } \\
\text { Populacional }\end{array}$ & Quantidade & \multicolumn{1}{c|}{ Municípios } \\
\hline $\begin{array}{c}\text { Acima de } \\
100.000\end{array}$ & 2 & Araguaína - Palmas \\
\hline $\begin{array}{c}\text { Entre 10.001 e } \\
100.000\end{array}$ & 25 & $\begin{array}{l}\text { Araguatins - Arraias - Augustinópolis - Babaçulândia - Colinas do Tocantins - } \\
\text { Dianópolis - Formoso do Araguaia - Goiatins - Guaraí - Gurupi - Lagoa da Confusão } \\
\text { - Miracema do Tocantins - Miranorte - Nova Olinda - Paraíso do Tocantins - Paranã } \\
\text { - Pedro Afonso - Peixe - Piraquê - Porto Nacional - São Miguel do Tocantins - } \\
\text { Taguatinga - Tocantinópolis - Wanderlândia - Xambioá }\end{array}$ \\
\hline $\begin{array}{c}\text { Entre 5.000 e } \\
10.000\end{array}$ & $\begin{array}{l}\text { Aguiarnópolis - Aliança do Tocantins - Almas - Alvorada - Ananás - Aragominas - } \\
\text { Araguacema - Araguacu - Araguanã - Arapoema - Axixá do Tocantins - Barrolândia } \\
\text { - Brejinho de Nazaré - Buriti do Tocantins - Campos Lindos - Colmeia - Couto } \\
\text { Magalhães - Cristalândia - Darcinópolis - Divinópolis do Tocantins - Dois Irmãos do } \\
\text { Tocantins - Esperantina - Figueirópolis - Filadélfia - Itacajá - Itaguatins - Monte do } \\
\text { Carmo - Natividade - Palmeiras do Tocantins - Palmeirópolis - Pequizeiro - Pium - } \\
\text { Ponte Alta do Tocantins - Praia Norte - Rio Sono - Santa Fé do Araguaia - Silvanópolis } \\
\text { - Sítio Novo do Tocantins - Tocantínia }\end{array}$ \\
\hline
\end{tabular}

Com o intuito de verificar a usabilidade e acessibilidade dos sítios eletrônicos e identificar as evidenciações compulsórias e voluntárias, os dados foram coletados a partir dos portais eletrônicos oficiais dos 66 municípios de Tocantins. Para identificação dos sítios oficiais dos municípios, foi utilizada a ferramenta de busca do Google $\AA$ (http://www.google.com.br), pesquisando a expressão: "prefeitura municipal de (nome da cidade)", validando apenas as páginas com essa denominação e com a extensão ".gov.br". A coleta de dados ocorreu no interstício de março a julho de 2017.

Para subsidiar a análise dos portais municipais foi adotado o modelo de Silva (2013). Esse modelo suporta a discussão da temática desse artigo, já que apresenta um conjunto de 32 indicadores que abrangem as informações compulsórias baseadas na Lei de Responsabilidade Fiscal (LRF) e na Lei de Acesso à Informação. A ideia básica esteve centrada em buscar melhores formas de descrever as iniciativas de divulgação de informações públicas através da aplicação de indicadores para a avaliação dos graus e níveis de transparência alcançados nas experiências de promovidas pelos governos municipais tocantinenses. 
Nesta pesquisa foram utilizados os mesmos indicadores, apontados nos quadros 3 e 4 . Para a identificação do atendimento ou não, a pesquisa iniciou-se no portal da transparência, depois na página inicial, no mapa do site e, por último, recorreu-se à ferramenta de pesquisa, quando esta era disponibilizada e estava disponível e funcionando corretamente. Nesse exame, os indicadores que foram evidenciados receberam a pontuação 1, e os que não, receberam 0.

\begin{tabular}{|c|c|c|c|}
\hline \multirow{2}{*}{\multicolumn{4}{|c|}{ Indicadores de Conformidade LRF }} \\
\hline & & & \\
\hline \multirow{16}{*}{$\begin{array}{c}\text { LRF } \\
(16 \text { pontos })\end{array}$} & 1) & Plano Plurianual (PPA) vigente & Art. 48 \\
\hline & & Plano Plurianual (PPA) anteriores & Art. 48 \\
\hline & & Lei de Diretrizes Orçamentárias (LDO) vigente & Art. 48 \\
\hline & & Lei de Diretrizes Orçamentárias (LDO) anteriores & Art. 48 \\
\hline & & Lei Orçamentária Anual (LOA) vigente & Art. 48 \\
\hline & 6) & Lei Orçamentária Anual (LOA) anteriores & Art. 48 \\
\hline & & Relatório Resumido de Execução Orçamentária (RREO) & Art. 48 \\
\hline & & Relatório de Gestão Fiscal (RGF) & Art. 48 \\
\hline & 9) & Versão simplificada RREO & Art. 48 \\
\hline & 10) & Versão simplificada RGF & Art. 48 \\
\hline & 11) & Relatório de prestação de contas & Art. 48 \\
\hline & 12) & Parecer Prévio de Prestação de Contas & Art. 48 \\
\hline & & $\begin{array}{l}\text { Incentivo à participação popular e audiências públicas no processo de elaboração e } \\
\text { discussão do PPA, LDO e LOA }\end{array}$ & Art. 48 \\
\hline & 14) & Informações de execução orçamentária e financeira em tempo real & Art. 48 \\
\hline & 15) & $\begin{array}{l}\text { Divulgação das datas das audiências públicas durante o processo de elaboração e } \\
\text { discussão do PPA, LDO e LOA }\end{array}$ & Art. 9 \\
\hline & 16) & $\begin{array}{l}\text { Divulgação das datas das audiências públicas quadrimestrais para avaliação das } \\
\text { metas fiscais }\end{array}$ & Art. 9 \\
\hline
\end{tabular}

Fonte: Silva (2013).

Nos indicadores referentes ao PPA, considerou-se "vigente" o PPA concernente ao período de 2014 a 2017, e "anteriores" o de 2010 a 2013 ou 2006 a 2009. Nos indicadores pertinentes a LDO e LOA, validouse como "vigente" as leis pertinentes ao ano de 2017, e "anteriores" qualquer uma do período de 2000 a 2016. No indicador de informações em tempo real, foram admitidas quando atendiam o Decreto n 7.185/2010, estando disponível até o primeiro dia útil subsequente à data do registro contábil. O quadro 4 apresenta os indicadores associados à LAI.

\begin{tabular}{|c|c|c|c|}
\hline \multicolumn{4}{|c|}{ Quadro 4 - Indicadores de Conformidade da Lei de Acesso à Informação } \\
\hline Parâmetros & & Indicadores de Conformidade LAI & Base Legal \\
\hline \multirow{16}{*}{$\begin{array}{c}\text { LAI } \\
\text { (16 pontos) }\end{array}$} & & Indicação clara de acesso a Lei de Acesso à Informação (LAI) & Art. 5 \\
\hline & & Indicação de meios para solicitação de informações & Art. 6 \\
\hline & & Criação do serviço de informações ao cidadão - SIC & Art. 9 \\
\hline & & Informações quanto às suas competências & Art. 8 \\
\hline & & Informações quanto à estrutura organizacional & Art. 8 \\
\hline & & Divulgação do endereço, telefones e horários de atendimento da(s) unidade(s) & Art. 8 \\
\hline & & Informações relativas aos repasses ou transferências de recursos & Art. 8 \\
\hline & & Informações sobre despesas realizadas & Art. 8 \\
\hline & & Informações sobre licitações, editais e resultados dos certames & Art. 8 \\
\hline & & Informações sobre contratos celebrados & Art. 8 \\
\hline & & Informações para acompanhamento de programas, ações, projetos e obras & Art. 8 \\
\hline & & Disponibilidade de "resposta e perguntas" mais frequentes FAQ & Art. 8 \\
\hline & & Disponibilidade de ferramentas de pesquisa & Art. 8 \\
\hline & & Permissão para gravação de relatórios eletrônicos & Art. 8 \\
\hline & & Atualização das informações disponibilizadas & Art. 8 \\
\hline & 16 & Disponibilidade de acesso às informações por pessoas com deficiência & Art. 8 \\
\hline
\end{tabular}
Fonte: Silva (2013).

Assim, foram avaliados os sites eletrônicos oficiais de cada um dos municípios da amostra, atribuindo 1 ponto quando o indicador foi evidenciado, e 0 quando não constava a informação do referido indicador. Isto posto, a pontuação dos indicadores da LRF poderia variar entre 0 e 16, e da LAl também de 0 a 16, perfazendo a escala que variou entre 0 a 32. Concluída a apuração dessas pontuações, o valor total foi transformado em percentual, dividindo o somatório dos pontos do município pela pontuação máxima possível. Posteriormente, foram construídos índices analisados por meio de estatística descritiva. Para tanto, foi estruturado o Índice de Conformidade com a LRF (IC LRF), o Índice de Conformidade com a LAI (IC LAI) e o Índice de Conformidade Geral (IC Geral). 
Em seguida, os sítios eletrônicos foram reanalisados, simultaneamente, quanto à usabilidade e acessibilidade, conforme os critérios estabelecidos por Amorim (2012), Amorim e Almada (2016) que estão elencados nos quadros 5 e 6.

\begin{tabular}{|c|c|}
\hline $\begin{array}{l}\text { Aspectos } \\
\text { avaliados }\end{array}$ & Critérios de análise \\
\hline $\begin{array}{c}\text { Mecanismos de } \\
\text { busca } \\
\text { (desejável) }\end{array}$ & $\begin{array}{l}\text { Muito bom - quando o portal fornece mecanismo de busca na página principal com ferramentas de } \\
\text { busca avançada. } \\
\text { Regular - quando o portal fornece mecanismo de busca na página principal, mas não fornece } \\
\text { possibilidade de pesquisa avançada. } \\
\text { Não existe - quando não existe mecanismo de busca na página principal. }\end{array}$ \\
\hline $\begin{array}{l}\text { Mapa do site } \\
\text { (desejável) }\end{array}$ & $\begin{array}{l}\text { Localizado - quando o portal fornece mapa do site na página principal. } \\
\text { Não localizado - quando o portal não fornece mapa do site na página principal. }\end{array}$ \\
\hline $\begin{array}{l}\text { Reconhecimento } \\
\text { e } \\
\text { Orientação do } \\
\text { sistema } \\
\text { (desejável) }\end{array}$ & $\begin{array}{l}\text { Muito bom - quando as páginas possuem títulos de identificação tanto nas barras de janela como } \\
\text { na área de conteúdo; a estrutura de organização hierárquica das informações do site favorece a } \\
\text { aprendizagem e a memorização do usuário; há facilidade de navegar entre as diferentes seções do } \\
\text { site a partir de qualquer página; e o site fornece identificação da instituição e referências para contato } \\
\text { em todas as páginas. } \\
\text { Bom - quando as páginas possuem títulos de identificação apenas nas barras de janela; a estrutura } \\
\text { de organização hierárquica das informações do site favorece a memorização do usuário; a facilidade } \\
\text { de navegar entre as diferentes seções do site requer o retorno para a página inicial; e o site fornece } \\
\text { identificação da instituição e referências para contato em algumas páginas. } \\
\text { Regular - quando o reconhecimento e a orientação do sistema são limitados pela dificuldade de } \\
\text { identificar os títulos das páginas; as informações não estão organizadas hierarquicamente, é difícil } \\
\text { a navegação entre as páginas do site; e falta a identificação da instituição nas páginas e as } \\
\text { referências de contato. } \\
\text { Fraco - quando o reconhecimento e a orientação do sistema são muito limitados pela dificuldade } \\
\text { de identificar os títulos das páginas; as informaçóes totalmente desorganizadas, é difícil a navegação } \\
\text { entre as páginas do site; e falta, em todas as páginas a identificação da instituição e as referências } \\
\text { de contato. } \\
\text { Não atende - quando não há condições para o usuário reconhecer o conteúdo e se orientar na } \\
\text { navegação. }\end{array}$ \\
\hline $\begin{array}{l}\text { Interface } \\
\text { (desejável) }\end{array}$ & $\begin{array}{l}\text { Muito bom - quando o aspecto visual do site é atraente e adequado; os elementos de informação } \\
\text { estão dispostos nas páginas de forma organizada e racional; há boa distinção visual entre os } \\
\text { diferentes elementos de interface, elementos de navegação, elementos de conteúdo; são usadas } \\
\text { variações de hierarquia tipográfica para distinguir as diferentes partes do texto, de forma clara e } \\
\text { organizada. } \\
\text { Bom - quando o aspecto visual do site é adequado; os elementos de informação estão dispostos } \\
\text { nas páginas de forma organizada; há distinção visual entre os diferentes elementos de interface, } \\
\text { elementos de navegação, elementos de conteúdo; as variações de hierarquia tipográfica não } \\
\text { facilitam a distinção das diferentes partes do texto. } \\
\text { Regular - quando o aspecto visual do site não é adequado; os elementos de informação estão } \\
\text { dispostos nas páginas de forma organizada; há distinção visual entre os diferentes elementos de } \\
\text { interface, elementos de navegação, elementos de conteúdo; as variações de hierarquia tipográfica } \\
\text { não facilitam a distinção das diferentes partes do texto. } \\
\text { Fraco - quando o aspecto visual do site não é adequado; os elementos de informação não estão } \\
\text { dispostos nas páginas de forma organizada; há distinção visual entre os diferentes elementos de } \\
\text { interface, elementos de navegação, elementos de conteúdo; as variações de hierarquia tipográfica } \\
\text { não facilitam a distinção das diferentes partes do texto. } \\
\text { Não existe - quando os elementos da interface do portal não favorecem o uso e movimentação do } \\
\text { usuário. }\end{array}$ \\
\hline
\end{tabular}

Fonte: Amorim (2012) e Amorim e Almada (2016).

Quadro 6 - Aspectos avaliados na categoria acessibilidade

\begin{tabular}{|c|l|}
\hline $\begin{array}{c}\text { Aspectos } \\
\text { avaliados }\end{array}$ & \multicolumn{1}{|c|}{ Critérios de análise } \\
\hline $\begin{array}{c}\text { Outros idiomas } \\
\text { (desejável) }\end{array}$ & $\begin{array}{l}\text { Muito bom - quando o portal oferece a opção de escolher outros idiomas para o usuário. } \\
\text { Regular - quando há a opção de escolher outros idiomas na página secundária. } \\
\text { Não existe - quando o portal não oferece a opção de outros idiomas para o usuário. }\end{array}$ \\
\hline $\begin{array}{c}\text { Acesso a } \\
\text { portadores de } \\
\text { necessidades } \\
\text { especiais } \\
\text { (essencial) }\end{array}$ & $\begin{array}{l}\text { Muito bom - quando o portal oferece funcionalidades para o acesso aos portadores de } \\
\text { necessidades especiais e ainda contém indicação de certificação de acessibilidade por órgão } \\
\text { competente. } \\
\text { Regular - quando o portal oferece funcionalidades para o acesso aos portadores de necessidades } \\
\text { especiais. } \\
\text { Não existe - quando o portal não oferece a opção para o acesso aos portadores de necessidades } \\
\text { especiais. }\end{array}$ \\
\hline
\end{tabular}




\begin{tabular}{|c|c|}
\hline $\begin{array}{l}\text { Aspectos } \\
\text { avaliados }\end{array}$ & Critérios de análise \\
\hline $\begin{array}{c}\text { Multiplicidade de } \\
\text { acesso } \\
\text { (desejável) }\end{array}$ & $\begin{array}{l}\text { Muito bom - quando o portal fornece aplicativos para que o usuário possa acessá-lo através de } \\
\text { dispositivos móveis. } \\
\text { Regular - quando alguns serviços podem ser acessados por dispositivos móveis. } \\
\text { Não existe - quando o portal nâo oferece aplicativos para que o usuário possa acessá-lo através de } \\
\text { dispositivos móveis. }\end{array}$ \\
\hline $\begin{array}{l}\text { Flexibilidade e } \\
\text { eficiência do } \\
\text { portal } \\
\text { (desejável) }\end{array}$ & $\begin{array}{l}\text { Muito bom - quando o site permite atingir o conteúdo de interesse com um mínimo de cliques; o } \\
\text { site permite fazer o bookmark das páginas de interesse para consulta futura, garantindo também a } \\
\text { manutenção da referência ao longo do tempo; as páginas do site imprimem sem perder formatação. } \\
\text { Bom - quando o site permite atingir o conteúdo de interesse com mais de três cliques; o site permite } \\
\text { fazer o bookmark das páginas de interesse para consulta futura, mas não garante a manutenção da } \\
\text { referência ao longo do tempo; páginas do site imprimem, mas perdem a formatação. } \\
\text { Regular - quando o site permite atingir o conteúdo de interesse com mais de quatro cliques; o site } \\
\text { não permite fazer o bookmark das páginas de interesse para consulta futura, não garante a } \\
\text { manutenção da referência ao longo do tempo; as páginas do site imprimem com perda da } \\
\text { formatação. } \\
\text { Fraco - quando o acesso ao conteúdo de interesse do site é difícil; o site não permite fazer o } \\
\text { bookmark das páginas de interesse para consulta futura, não garante a manutenção da referência } \\
\text { ao longo do tempo; não é possível imprimir as páginas do site. } \\
\text { Não existe - quando o portal não fornece funcionalidades que tornem o uso do portal flexível e } \\
\text { eficiente. }\end{array}$ \\
\hline $\begin{array}{l}\text { Linguagem de } \\
\text { programação e } \\
\text { desenvolvedor } \\
\text { (desejável) }\end{array}$ & $\begin{array}{l}\text { Muito bom - quando o portal publica a linguagem utilizada e o responsável (próprio ou terceirizado) } \\
\text { pelo desenvolvimento do portal. } \\
\text { Regular - quando o portal publica o responsável (próprio ou terceirizado) pelo desenvolvimento do } \\
\text { portal ou a linguagem utilizada. } \\
\text { Não existe - quando o portal não publica a linguagem utilizada e o responsável pelo } \\
\text { desenvolvimento do portal. }\end{array}$ \\
\hline
\end{tabular}
Fonte: Amorim (2012) e Amorim e Almada (2016).

Após realização dessas combinações em toda a amostra, foram elaborados percentuais para apresentação do comportamento da amostra, consonante à usabilidade e acessibilidade, via estatística descritiva.

\section{Apresentação e Discussão dos Resultados}

Esta seção identifica os dados coletados, apontando a conformidade dos municípios, por faixa populacional, em relação à LRF e à LAl. Também os portais eletrônicos das prefeituras foram caracterizados quanto à usabilidade e acessibilidadei.

\subsection{Conformidade da Amostra em Relação à LRF e LAI}

No decorrer das análises observou-se que os sites oficiais dos 137 municípios que fazem parte da amostra foram avaliados em relação ao atendimento a alguns indicadores constantes da LRF e da LAI, sendo 16 de cada normativo, e 32 no geral. Notou-se que a maior diferença possível encontrada entre os percentuais foi de $68,75 \%$ (intervalo). A curtose de $-1,50$ caracteriza que a dispersão desta distribuição é leptocúrtica, com os dados bem concentrados em torno do seu centro, mas não tanto concentrada quanto ao IC LAI. Por fim, a assimetria de 0,31 revela o comportamento da distribuição dos índices, sendo assimétrica positiva e moderada, com mediana maior que a moda e menor que a média (tabela 1).

Tabela 1 - Estatística descritiva dos índices de transparência pública (IC LRF, IC LAI e IC Geral)

\begin{tabular}{lccc}
\hline \multicolumn{1}{c}{ Estatística Descritiva } & IC LRF & IC LAI & IC GERAL \\
\hline Média (\%) & 23,20 & 69,32 & 46,26 \\
Erro Padrão (\%) & 2,88 & 2,00 & 2,10 \\
Mediana (\%) & 21,88 & 68,75 & 46,88 \\
Moda (\%) & 0,00 & 68,75 & 25,00 \\
Desvio Padrão (\%) & 23,41 & 16,25 & 17,05 \\
Variância da Amostra (\%) & 5,48 & 2,64 & 2,91 \\
Curtose & $-1,50$ & $-0,72$ & $-0,96$ \\
Coeficiente de Variação (CV) & 1,01 & 0,23 & 0,37 \\
Assimetria & 0,31 & $-0,19$ & 0,22 \\
Intervalo (\%) & 68,75 & 68,75 & 68,75 \\
Mínimo (\%) & 0,00 & 31,25 & 15,63 \\
Máximo (\%) & 68,75 & 100,00 & 84,38 \\
\hline Total de municípios & 66 & 66 & 66 \\
\hline
\end{tabular}

Fonte: Dados da pesquisa, 2018. 
A estatística descritiva do IC LRF exprime que, nos aspectos das medidas de dispersão, o erro padrão (desvio padrão das médias) foi de 2,88\%; a variância 5,48\%, evidenciando haver mais valores distantes da média do que o IC LAl; e o desvio padrão $23,41 \%$, refletindo uma maior variabilidade dos valores em relação à média do que o IC LAI. No tocante às medidas de tendência central, a média do cumprimento a LRF foi apenas de $23,20 \%$, sendo esse baixo percentual retratado no Gráfico 1.

O baixo índice da média resulta do fato de que 28 municípios obtiveram a pontuação mínima, zero, enquanto 2 alcançaram $68,75 \%$, o maior índice encontrado nesse quesito, fato este justificável por serem os municípios com maior faixa populacional. Em sua pesquisa Souza et al encontrou resultado similar, já que identificou que a maior parte dos municípios não possui sítio próprio na internet. Nenhum dos municípios contidos na amostra divulgou todas as informações requeridas pela LRF em seus sítios. Observou-se uma grande diferença entre as informações evidenciadas por diferentes mesorregiões, e acredita-se que a questão econômica seja um dos principais fatores que levam a essa discrepância.

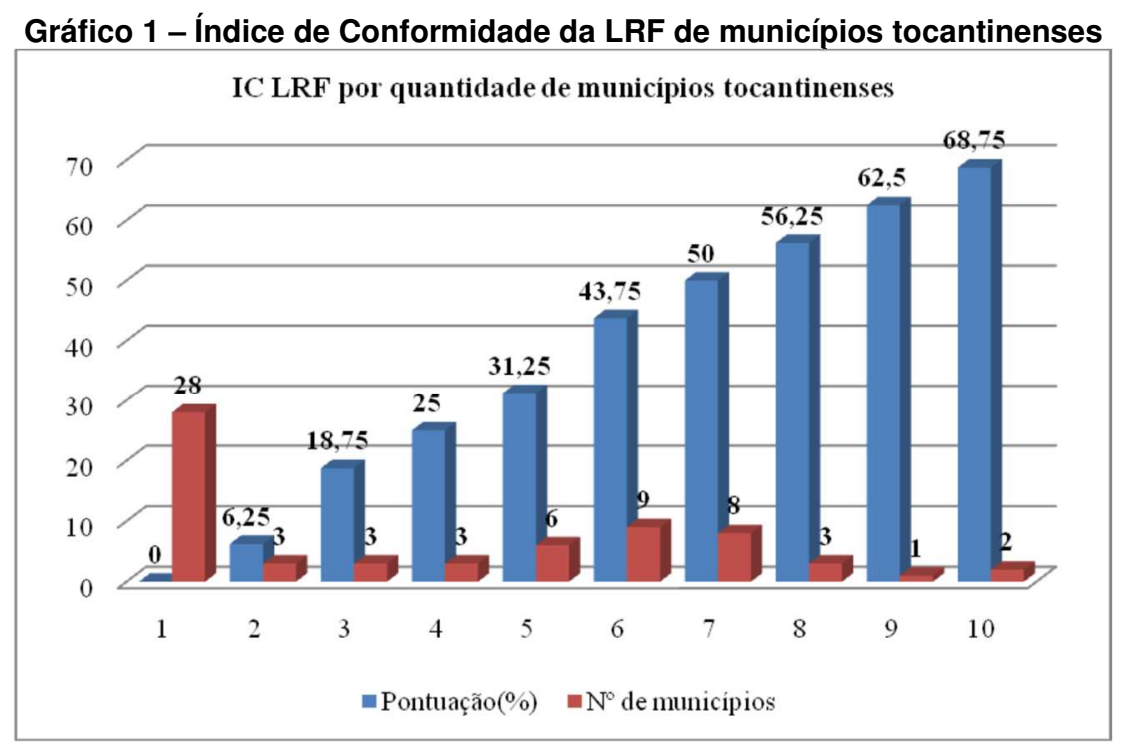

Fonte: Dados da pesquisa, 2018.

Os índices apresentados no gráfico 2 simbolizam a aderência dos municípios tocantinenses à LAl. Os percentuais se referem ao cumprimento dos indicadores relacionados no quadro 4. Apenas o município de Gurupi alcançou 100,00\%, e o menor índice, 31,25\%, foi obtido por Axixá do Tocantins. Relativo ainda às medidas de posição descritas na Tabela 1, a moda de $68,75 \%$ indica que este foi o porcentual mais encontrado, medido em 11 municípios. De certa forma, todos os indicadores foram satisfeitos por algum município, o menos atendido foi o indicador 4 (informações quanto às suas competências), implementado por 12 municípios; destarte que 64 municípios apresentaram indicação clara de acesso à LAl (indicador 1) e de meios para solicitação de informações (indicador 2), sendo que exclusivamente o município de Buriti não atendeu a esses indicadores.

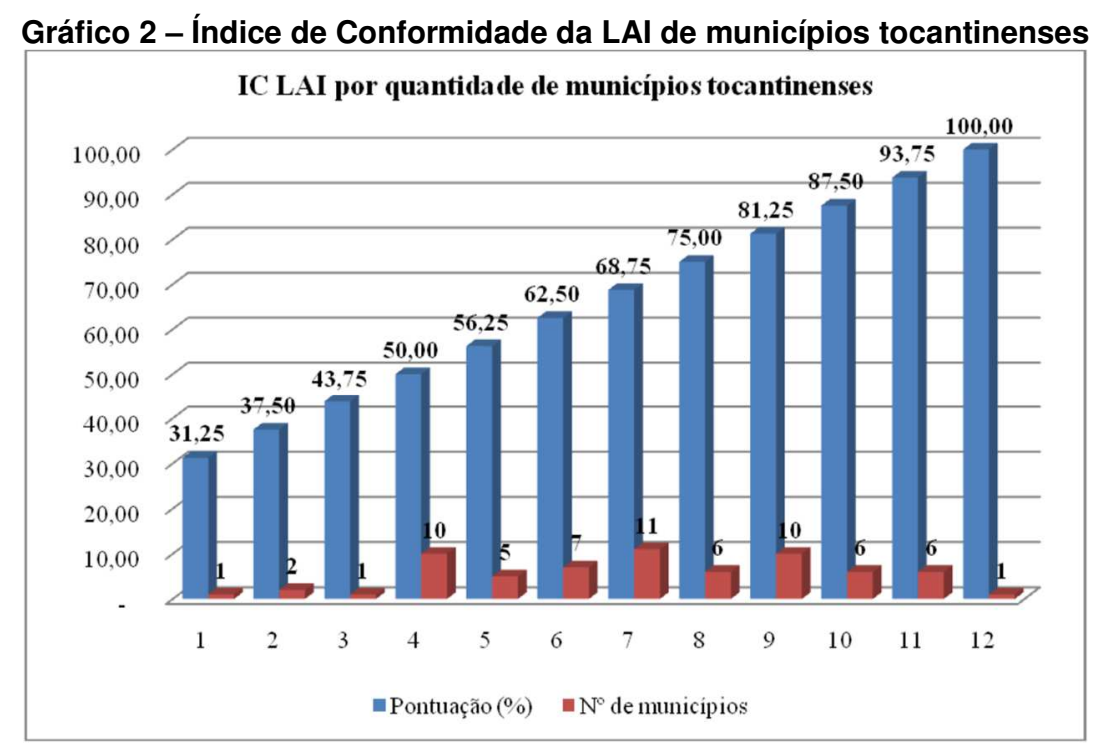

Fonte: Dados da pesquisa, 2018. 
Cruz et al. (2012) encontraram o nível de transparência das informações acerca da gestão pública divulgadas nos portais eletrônicos de 96 municípios entre os 100 mais populosos do Brasil, tendo como resultado que os municípios da amostra não divulgaram as informações de forma completa.

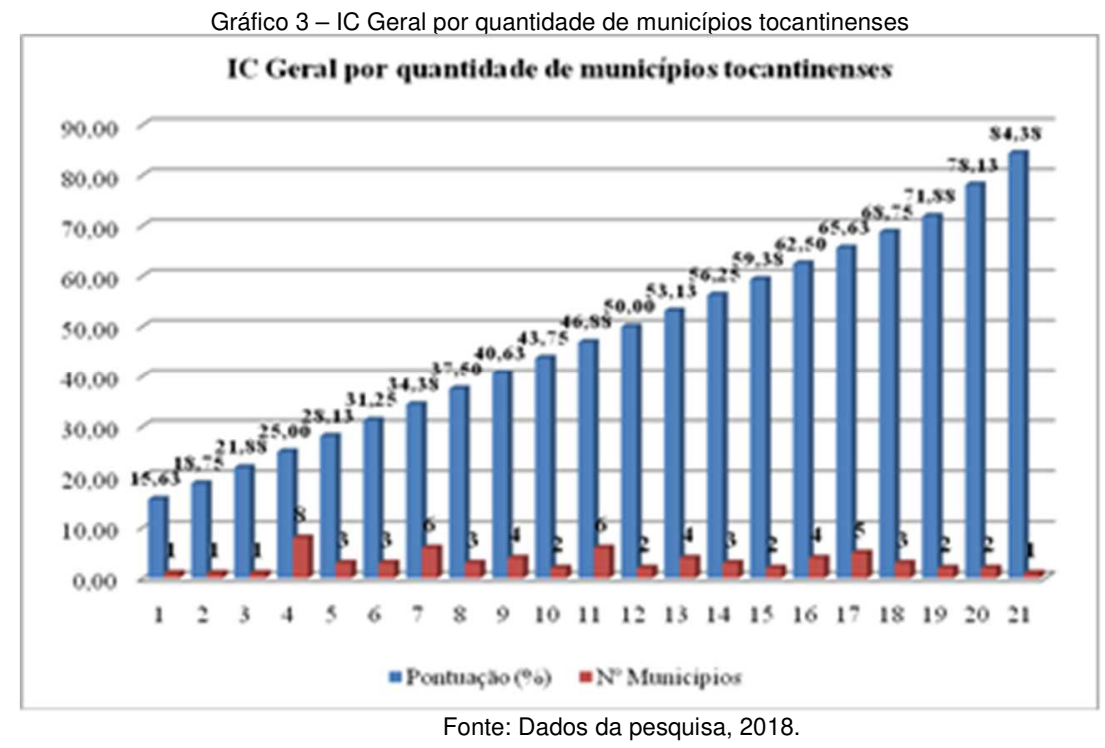

A análise apresentada contemplou toda a amostra, caracterizando a transparência pública de municípios tocantinenses quanto à observância da LRF e da LAI. Entretanto, para que fosse possível identificar se haveria divergência na transparência devido à LAI dispensar os municípios com população de até 10.000 habitantes a publicar informações públicas em sítios oficiais na internet, cabe averiguar a transparência por legislação e por faixa populacional da amostra.

\subsection{Aderência dos Municípios Tocantinenses à LRF}

A aderência dos municípios tocantinenses à LRF foi obtida por faixa populacional, investigando a obediência à legislação mencionada dos que possuem mais de 100.000 habitantes, entre 10.001 e 100.000 e entre 5.000 e 10.000 .

No estado do Tocantins apenas 2 municípios contam com mais de 100.000 habitantes, sendo Araguaína e Palmas. Essas cidades apresentam porcentuais de atendimento à LRF bem distintos, pois enquanto Araguaína tem o IC LRF de 6,25\%, por atender apenas um indicador dos constantes no quadro 2 , (publicação de informações sobre a execução orçamentária em tempo real, indicador 14), Palmas obteve o IC LRF de 68,75\%, respeitando 11 dos indicadores considerados (indicadores 1, 2, 3, 4, 6, 7, 8, 9, 10, 12 e 14), conforme aponta a tabela 2.

Tabela 2 - Aderência dos municípios tocantinenses por faixa populacional aos indicadores da LRF

\begin{tabular}{|c|c|c|c|c|c|}
\hline \multirow{2}{*}{\multicolumn{2}{|c|}{ Indicadores de Conformidade LRF }} & \multicolumn{4}{|c|}{ Entre 10.001 e 100.000} \\
\hline & & Total & $\%$ & Total & $\%$ \\
\hline & Plano Plurianual (PPA) vigente & 13 & 52 & 14 & 36 \\
\hline 2) & Plano Plurianual (PPA) anteriores & 6 & 24 & 8 & 21 \\
\hline 3) & Lei de Diretrizes Orçamentárias (LDO) vigente & 4 & 16 & 7 & 18 \\
\hline 4) & Lei de Diretrizes Orçamentárias (LDO) anteriores & 12 & 48 & 16 & 41 \\
\hline 5) & Lei Orçamentária Anual (LOA) vigente & 4 & 16 & 6 & 15 \\
\hline 6) & Lei Orçamentária Anual (LOA) anteriores & 12 & 48 & 15 & 38 \\
\hline 7) & Relatório Resumido de Execução Orçamentária (RREO) & 13 & 52 & 15 & 38 \\
\hline 8) & Relatório de Gestão Fiscal (RGF) & 13 & 52 & 15 & 38 \\
\hline 9) & Versão simplificada RREO & 11 & 44 & 13 & 33 \\
\hline 10) & Versão simplificada RGF & 12 & 48 & 13 & 33 \\
\hline 11) & Relatório de prestação de contas & 2 & 8 & 0 & 0 \\
\hline 12) & Parecer Prévio de Prestação de Contas & 1 & 4 & 0 & 0 \\
\hline 13) & Incentivo à participação popular e audiências públicas no proc. elaboração e discussão do PPA, LDO e LOA & 2 & 8 & 0 & 0 \\
\hline 14) & Informações de execução orçamentária e financeira em tempo real & 3 & 12 & 2 & 5 \\
\hline 15) & Divulgação das datas das audiências públicas durante o proc. elaboração e discussão do PPA, LDO e LOA & 1 & 4 & 0 & 0 \\
\hline 16) & Divulgação das datas das audiências públicas quadrimestrais para avaliação das metas fiscais & 0 & 0 & 0 & 0 \\
\hline
\end{tabular}

Observação: A faixa populacional foi suprimida da tabela em razão da quantidade de municípios. Fonte: Dados da pesquisa, 2018. 
Nenhum dos indicadores foi atendido por todos os municípios, não houve comunicação de datas das audiências públicas quadrimestrais para avaliação das metas fiscais (indicador 16); exclusivamente Tocantinópolis divulgou as datas das audiências públicas durante o processo de elaboração e discussão do PPA, LDO e LOA (indicador 15); e apenas Gurupi havia publicado o parecer prévio de prestação de contas (indicador 12). Os indicadores mais atendidos foram quanto as publicações do plano plurianual vigente (indicador 1), do RREO (indicador 7) e do RGF (indicador 8) de algum período que foram evidenciados por 13 municípios distinto (tabelas 2 e 3 ).

Nos municípios com população maior que 100.000 habitantes e entre 10.001 e 100.000, em média, a obediência das prefeituras à LRF foi muito baixa. $O$ atendimento à LRF dos 39 municípios tocantinenses que possuem entre 5.000 e 10.000 habitantes foi evidenciado em 16 indicadores, todavia cinco não foram atendidos por nenhum município. Os municípios de Araguacema e Araguanã são os únicos, nesse conjunto, que prestaram informações sobre a execução orçamentária e financeira em tempo real (indicador 14). $O$ indicador mais respeitado foi o 5 (Lei orçamentária anual - LOA vigente), pois 16 municípios disponibilizaram a LDO anterior a 2017. É nítido que esses municípios apresentam menor conformidade à LRF do que aqueles com maior quantitativo populacional, reforçando a tese levantada por Vieira, Bianchi e Kronbauer (2017) quando estudaram os municípios do Rio Grande do Sul e Leite Filho, Vieira Colares e Andrade (2015) quando estudaram os municípios e Minas Gerais

Observa-se, em outra linha de pensamento, que o resultado evidenciado vai em desencontro com o afirmado também por Bairral; Silva e Alves (2015) quando afirmam que à medida que a administração pública é transparente, evidenciando amplamente as ações tomadas pela gestão, reduz a assimetria informacional entre a sociedade e o Estado e permite o controle por parte dos órgãos competentes e também pela sociedade, desta forma o resultado pode indicar falta de transparência.

Tabela 3 - Estatísticas do IC LRF dos municípios tocantinenses por faixa populacional

\begin{tabular}{lccc}
\hline Estatística Descritiva & IC LRF & $\begin{array}{c}\text { IC LRF } \\
\text { (Acima de 100.000 hab.) }\end{array}$ & $\begin{array}{c}\text { IC LRF } \\
\text { (Entre 10.001 e 100.000 } \\
\text { hab.) }\end{array}$ \\
\hline Média (\%) & 37,50 & 27,25 & $\begin{array}{c}\text { (Entre 5.000 e } 10.000 \\
\text { hab.) }\end{array}$ \\
Erro Padrão (\%) & 31,25 & 5,16 & 19,87 \\
Mediana (\%) & 37,50 & 31,25 & 3,33 \\
Moda (\%) & $*$ & 0,00 & 18,75 \\
Desvio Padrão (\%) & 44,19 & 25,82 & 0,00 \\
Variância da Amostra (\%) & 19,53 & 6,67 & 20,77 \\
Curtose & $*$ & $-1,81$ & 4,31 \\
Assimetria & $*$ & 0,02 & $-1,55$ \\
Intervalo (\%) & 62,50 & 68,75 & 0,37 \\
Mínimo (\%) & 6,25 & 0,00 & 56,25 \\
Máximo (\%) & 68,75 & 68,75 & 0,00 \\
Total de municípios & 2 & 25 & 56,25 \\
\hline
\end{tabular}

Fonte: Dados da pesquisa, 2018.

Dessa forma, todos 66 municípios tocantinenses examinados demonstraram menos da metade da conformidade possível, caracterizando a baixa transparência pública dos municípios tocantinenses.. Os resultados apontados pelo estudo aderem ao que foi encontrado por Leite Filho, Andrade e Colares (2015) quando apontaram para um nível de transparência fiscal ainda precário no Estado de Minas Gerais, tendo em vista que muitas informações encontradas nos Portais da Transparência eram defasadas, não pormenorizadas, indisponíveis e de difícil localização e entendimento.

\subsection{Aderência dos Municípios Tocantinenses à LAI}

A aderência dos municípios da amostra à LAl aponta para um cenário em que quase todos os indicadores foram atendidos pelos 2 municípios (12 dos 16 analisados). No momento da coleta, apenas Araguaína prestou informações relativas a repasses ou transferências de recursos (indicador 7), contudo somente Palmas divulgou informações para acompanhamento de programas, ações, projetos e obras (indicador 11) e disponibilizou acesso a informações por pessoas com deficiências (indicador 16).

Apenas o indicador 1 foi observado por todos os municípios, os 25 sites continham identificação clara de acesso à LAl; já o indicador menos verificado foi relacionado às informações quanto às suas competências (indicador 4), localizado em 6 municípios, seguido pelo indicador 10 (informações sobre contratos celebrados), pois apenas 9 municípios prestaram alguma informação sobre contrato celebrados.

As estatísticas obtidas caracterizam a baixa dispersão das observações em relação à média (tabela 5). No que diz respeito aos municípios com menor população, mas ainda obrigados a disponibilizar tais informações em seus sítios eletrônicos, foi possível observar dentre os índices estimados nos 25 municípios 
Tabela 4 - Aderência dos municípios tocantinenses faixa populacional aos Indicadores da LAI

\begin{tabular}{|c|c|c|c|c|c|c|c|}
\hline & \multirow{2}{*}{ Indicadores da Corfomidads LAI } & \multicolumn{2}{|c|}{ Acina de 100.000} & \multicolumn{2}{|c|}{ Entre 10.001 e 100.000} & \multicolumn{2}{|c|}{ Entre $5.000=10.000$} \\
\hline & & Tora! & $\%$ & Toa! & $\%$ & Toa! & $\%$ \\
\hline 1) & Indiraçào clara da acesso a Lei de Acesso a Irform x̧ào (LAI) & 2 & 100 & 25 & 100 & 37 & 94,87 \\
\hline 2) & Indiraçào de meico para soliciaçào da informaçōes & 2 & 100 & 24 & 96 & 38 & 97.44 \\
\hline 3) & Criaçäo do serviço de informa,̧̄̇es ao cidadäo - SIC & 2 & 100 & 23 & 92 & 38 & 97,44 \\
\hline 4) & Iformaçòes quanto às suas coenpetêxias & 2 & 100 & 6 & 24 & 4 & 10,26 \\
\hline 5) & Ifformaçōes quanto à estutura orgarizaciona! & 2 & 100 & 16 & 64 & 19 & 48,72 \\
\hline 6) & Divúgrçào do endereço, telafores e horários de atendimento da(s) unideder(s) & 2 & 100 & 21 & 84 & 36 & 9231 \\
\hline 7) & Ifformaçōesrelativas aos repasses ou transféncias de recursos & 1 & 50 & 14 & 56 & 20 & 51.28 \\
\hline 8) & Ifformaçōes score dxpesas salizadas & 2 & 100 & 20 & 80 & 24 & 6154 \\
\hline 9) & Iformaçōes sobre licitaçōes, editais e resulados dos certanes & 2 & 100 & 16 & 64 & 12 & 30,77 \\
\hline 10) & Informaçōes sobe contratos celabrados & 2 & 100 & 9 & 36 & 16 & 4103 \\
\hline 11) & Iniomaçōes para acoen pentraenento de programas açōes projeto6 e obras & 1 & 50 & 11 & 44 & 18 & 46,15 \\
\hline 12) & Disponibilidede de "resposta e pergnus" mais fequentas FAQ & 0 & 0 & 21 & 84 & 33 & 84,62 \\
\hline 13) & Disponibilidada de ferramentas de pesquisa & 2 & 100 & 20 & 80 & 33 & 84,62 \\
\hline 14) & Perm issäo para gravação de relatóxios elatrónicos & 2 & 100 & 23 & 92 & 33 & 84,62 \\
\hline 15) & Arualizaçäo das ifformą̧ōes disporibilizades & 2 & 100 & 19 & 76 & 24 & 61.54 \\
\hline 16) & Disponibilidada de acesso as informaç̧òs por pesscas con defiziênxia & 1 & 50 & 18 & 72 & 34 & 87.18 \\
\hline
\end{tabular}

Fonte: Dados da pesquisa, 2019.

Acredita-se que os resultados deste estudo tendem a indicar aos gestores públicos e cidadãos dos municípios investigados um panorama da atual situação da transparência na gestão pública municipal no âmbito do Estado de Tocantins. Ao permitir aos cidadãos melhor conhecer o ambiente onde vivem e investem, espera-se que reflitam sobre a eficiência na gestão pública e a suficiência ou não das informações disponibilizadas, podendo intervir no processo de formulação de políticas públicas, auxiliando para o desenvolvimento regional. Além disso, estudos desta natureza têm o propósito de contribuir para que os gestores públicos analisem a forma como evidenciam a divulgação de informações em suas gestões, possibilitando orientá-los no desenvolvimento de políticas de disponibilização de informações claras e eficientes, o que pode auxiliar no estreitamento da relação governo cidadão, conforme defendem Visentini e Santos (2019).

Tabela 5 - Estatísticas do IC LAI dos municípios tocantinenses por faixa populacional

\begin{tabular}{l|c|c|c}
\hline Estatística Descritiva & $\begin{array}{c}\text { IC LAI } \\
\text { (Acima de 100.000 hab.) }\end{array}$ & $\begin{array}{c}\text { IC LAI } \\
\text { (Entre 10.001 e 100.000 } \\
\text { hab.) }\end{array}$ & $\begin{array}{c}\text { IC LAI } \\
\text { (Entre 5.000 e } 10.000 \\
\text { hab.) }\end{array}$ \\
\hline Média (\%) & 84,38 & 71,50 & 67,15 \\
Erro Padrão (\%) & 3,13 & 3,41 & 2,52 \\
Mediana (\%) & 84,38 & 68,75 & 68,75 \\
Moda (\%) & não há & 68,75 & 68,75 \\
Desvio Padrão (\%) & 4,42 & 17,03 & 15,75 \\
Variância da Amostra (\%) & 0,20 & 2,90 & 2,48 \\
Curtose & não há & $-0,86$ & $-0,64$ \\
Assimetria & não há & $-0,09$ & $-0,23$ \\
Intervalo (\%) & 6,25 & 62,50 & 62,50 \\
Mínimo (\%) & 81,25 & 37,50 & 31,25 \\
Máximo (\%) & 87,50 & 100,00 & 93,75 \\
Total de municípios & 2 & 25 & 39 \\
\hline
\end{tabular}

Fonte: Dados da pesquisa, 2018.

Estes resultados são semelhantes aos resultados encontrados por Cruz et al. (2012), que identificaram que os municípios da amostra não divulgaram as informações de forma completa, apontando baixo nível de transparência. É possível observar também nestes resultados que os maiores munícipios trazem informações mais completas, corroborando com os achados na pesquisa de Pires et al. (2013), que maiores municípios de faixa populacional tendem a atender mais os indicadores da LAI.

\subsection{Acessibilidade dos Sítios Eletrônicos da Amostra}

Evidenciar as informações requeridas em lei é um requisito muito importante a ser cumprido pelas prefeituras, mas o seu acesso pode ser dificultado ou até mesmo restrito dependendo de como estivem 
organizadas e de onde foram disponibilizadas. Os achados da pesquisa apontaram que os cinco aspectos foram contemplados em todos os municípios da amostra (tabela 6 ).

Nenhum dos sítios eletrônicos dos 66 municípios verificados oferece opção de outros idiomas para o usuário, estando disponíveis unicamente em Português. Relacionado ao acesso por portadores de necessidades especiais (PNE), nenhum indicou a certificação de acessibilidade, contudo $60,61 \%$ das prefeituras (40) oferecem alguma funcionalidade para o acesso a PNE, seja no portal da transparência ou na página inicial, sendo a maioria configurada para deficientes visuais, permitindo alterações no tamanho da fonte e contraste. Infelizmente, $39,39 \%$ (26) não fornecem nenhuma acessibilidade a PNE, mesmo esse aspecto sendo essencial. Em análise a multiplicidade de acesso, 64 websites $(96,97 \%)$ são regulares, sendo possível acessá-los através de dispositivo eletrônicos.

Tal resultado converge com o obtido na pesquisa de Silva; Segatto; Silva (2016), em que a totalidade dos municípios possui portais eletrônicos, todavia essa implantação não evidencia o disclosure. Nenhum dos municípios atende à totalidade das condições estabelecidas na LC № 131/2009 e alguns municípios dificultam o acompanhamento de informações disponibilizadas em tempo real por colocarem seus sítios eletrônicos em manutenção por longos espaços de tempo.

Tabela 6 - Acessibilidade da amostra de municípios tocantinenses

\begin{tabular}{ccc}
\hline Aspectos avaliados & Critérios de análise & Atendimento \\
\hline \multirow{2}{*}{ Outros idiomas } & Muito bom & $0,00 \%$ \\
& Regular & $0,00 \%$ \\
& Não existe & $100,00 \%$ \\
\hline \multirow{2}{*}{ Acesso a portadores de } & Muito bom & $0,00 \%$ \\
necessidades especiais & Regular & $60,61 \%$ \\
& Não existe & $39,39 \%$ \\
\hline \multirow{2}{*}{ Multiplicidade de acesso } & Muito bom & $0,00 \%$ \\
& Regular & $96,97 \%$ \\
& Não existe & $3,03 \%$ \\
\hline \multirow{3}{*}{ Flexibilidade e eficiência do } & Muito bom & $46,97 \%$ \\
portal & Bom & $15,15 \%$ \\
& Regular & $18,18 \%$ \\
& Fraco & $12,12 \%$ \\
\hline \multirow{2}{*}{ Linguagem de programação e } & Não existe & $7,58 \%$ \\
\hline desenvolvedor & Muito bom & $1,52 \%$ \\
& Regular & $92,42 \%$ \\
\hline
\end{tabular}

Fonte: Dados da pesquisa, 2019.

A flexibilidade e eficiência foram consideradas muito boas na maioria dos municípios, porque as páginas eletrônicas permitiram atingir o conteúdo de interesse com um mínimo de cliques, fazer o bookmark (favoritos) das páginas de interesse para consulta futura e as páginas do site imprimiram sem perder formatação. Em alguns casos foram necessários mais de três cliques para atingir o conteúdo de interesse, permitiram fazer o bookmark mas sem garantia da manutenção da referência ao longo do tempo e as páginas perderam a formatação ao serem impressas. Cabe ressaltar que foram caracterizadas como fracas, sendo ainda inferior ao conceito de bom, por ter sido necessário mais de 4 cliques para atingir como também o difícil acesso ao conteúdo de interesse no site o conteúdo de interesse e não permitir fazer o bookmark.

\subsection{Usabilidade dos Sítios Eletrônicos da Amostra}

$\mathrm{Na}$ categoria usabilidade os websites das 137 prefeituras da amostra foram auferidos em busca de identificação da existência de mecanismo de busca no site e de mapa do site; de verificação da estrutura de organização hierárquica das informações, da navegação entre as diferentes seções do site e da indicação de referências para contato; e para observar o aspecto visual do site. A tabela 7 apresenta a usabilidade dos 66 sites oficiais das prefeituras do Tocantins.

Relativo à avaliação do aspecto mecanismos de busca, somente 6 municípios $(9,09 \%)$ forneceram mecanismo de busca na página principal com ferramentas de busca avançada; já a maioria, 53 (80,30\%), possuem o mecanismo, mas não há possibilidade de busca avançada; e em $7(10,61 \%)$ não existe o mecanismo. Verificando o mapa do site, só foi localizado na página principal de 26 prefeituras $(39,39 \%)$, não sendo localizado nas restantes, 40 (60,61\%).

Pertinente ao terceiro aspecto, reconhecimento e orientação do sistema, $15,15 \%$ (10) foram pontuados como muito bons devido às páginas possuírem títulos de identificação nas barras de janelas e na área de conteúdo, a estrutura hierárquica das informações do site favorecerem a aprendizagem e a memorização do usuário, a facilidade de navegar entre as diferentes seções do site a partir de qualquer página e por fornecer identificação da instituição e referências para contato em todas as páginas. A maioria, $62,12 \%$ 
(41) apresentam bom reconhecimento e orientação do sistema e $21,21 \%$ (14) regular em consequência da dificuldade de identificar os títulos das páginas, da falta de organização hierárquica das informações e da ausência de identificação da instituição nas páginas e as referências de contato.

Tabela 7 - Usabilidade da amostra de municípios tocantinenses

\begin{tabular}{ccc}
\hline Aspectos avaliados & Critérios de análise & Atendimento \\
\hline \multirow{2}{*}{ Mecanismos de busca } & Muito bom & $9,09 \%$ \\
& Regular & $80,30 \%$ \\
& Não existe & $10,61 \%$ \\
\hline \multirow{2}{*}{ Mapa do site } & Localizado & $39,39 \%$ \\
& Não localizado & $60,61 \%$ \\
\hline & Muito bom & $15,15 \%$ \\
Reconhecimento e orientação do & Bom & $62,12 \%$ \\
sistema & Regular & $21,21 \%$ \\
& Fraco & $1,52 \%$ \\
& Não atende & $0,00 \%$ \\
\hline & Muito bom & $21,21 \%$ \\
Interface & Bom & $53,03 \%$ \\
& Regular & $19,70 \%$ \\
\end{tabular}

Fonte: Dados da pesquisa, 2018.

A interface de $14(21,21 \%)$ dos websites foi apreciada como muito bons, com um aspecto visual atraente e adequado, apresentando os elementos de informação disposto nas páginas de forma organizada e racional, com boa distinção entre os diferentes elementos, e ainda distinguindo as diferentes partes do texto com variações de hierarquia tipográfica, de forma clara e organizada. A maior parte dos municípios, 35 $(53,03 \%)$ foram caracterizados como bons, correspondendo a um aspecto visual do site adequado, com elementos de informações dispostos de forma organizada, com distinção visual entre os diferentes elementos, porém as variações de hierarquia tipográfica não facilitam a distinção das diferentes partes do texto, seguindo de 13 municípios (19,70\%) com nível regular e 6,06\% fraco.

\section{Considerações Finais}

As evidências encontradas na pesquisa apontam para a necessidade e maior empenho por parte da gestão pública dos municípios tocantinenses em se submeterem à LRF e à LAI, uma vez que, há gestores públicos que, mesmo administrando uma cidade com população acima de 10.000 habitantes, não fornecem nem mesmo o mínimo pelas normas brasileira, e poucos também são os que a cumprem plenamente, conforme determina os dispositivos legais. Relativo aos municípios com população entre 5.000 e 10.000 habitantes, é evidente o fomento à transparência pelas evidenciações voluntárias observadas, sendo que alguns municípios dispensados de cumprirem a LAI atendem melhor a esse normativo legal do que os obrigados ao cumprimento.

É inegável que a maioria das prefeituras dos municípios avaliados atendem, em média, mais à LAI do que à LRF. É contraditório um município priorizar a adequação aos procedimentos de disponibilização de informações públicas, sem satisfazer normas básicas na gestão fiscal, pois não há coerência em fomentar a transparência de informações públicas sem acatar normas legais sobre o gerenciamento dos recursos públicos.

Avaliando a acessibilidade dos sites oficiais das prefeituras que fazem parte da amostra, observouse que apresentam uma transparência pública razoável nos aspectos quanto ao acesso por portadores de necessidades especiais e à flexibilidade e eficiência do portal. Percebeu-se também que a usabilidade, acessibilidade e acessibilidade tem sido adotada pelos portais, todavia ainda necessitam de maior empenho no sentido de atender plenamente aos aspectos obrigatórios e voluntários.

Estes resultados em termos comparativos com estudos anteriores realizados (SILVA, 2013; BAIRRAL; SILVA; ALVES, 2015; BERNARDES; SANTOS; ROVER, 2015; AMORIM; ALMADA, 2016), mostram similaridade entre os achados, o que emerge um resultado de que, embora seja o Estado do Tocantins o mais novo da federação brasileira, ele infere em práticas usuais de municípios mais antigos, comprometendo a transparência e as boas práticas inerentes a governança corporativa no setor público.

Nota-se, a partir do que foi estudado que ainda há um longo caminho a ser percorrido para que a transparência fiscal esta seja tratada como uma questão de prioridade pela gestão pública. Ficou claro que a divulgação dos dados e informações sobre a gestão pública não é totalmente feita em conformidade com a legislação, e há pouco incentivo à participação do cidadão nos processos de planejamento, acompanhamento e avaliação das ações do governo, o que não contribui para o controle social, corroborando os achados encontrados por Visentini e Santos (2019). 
Talvez essa constatação seja reflexo da flexibilidade que ainda permeia pelos órgãos de controle, da "pressão" da sociedade e dos vícios inerentes e presentes na administração pública que acaba por comprometer a forma como devem ser divulgadas as informações de natureza pública e consequentemente a responsabilidade social junto ao seu público de interesse e assim contribuir para a melhoria da gestão pública como forma de alcançar a sua legitimidade social e construir um vínculo de confiança, conforme defendem Beuren, Gubiani e Soares (2013).

Pesquisas futuras podem investigar os mesmos municípios, no entanto com um caráter longitudinal; ou ainda uma análise por mesorregião. Podem ser examinadas a qualidade das informações publicadas nos sítios oficias e se os serviços oferecidos estão em funcionamento (ex: e-sic). Recomenda-se também atrelar os índices medidos a outros parâmetros, que não seja faixa populacional, para verificar fatores que podem influenciá-los; verificar outras formas de evidenciação que não seja em websites.

\section{Referências}

AMORIM, P. K. D. F. Democracia e internet: a transparência de gestão nos portais eletrônicos das capitais brasileiras. 2012. Tese (Doutorado em Comunicação e Cultura Contemporânea) - Universidade Federal da Bahia (UFBA), Salvador, 2012.

AMORIM, P. K. D. F.; ALMADA, M. P. E-transparência: proposta de modelo metodológico para avaliação de portais de executivos nacionais. Logos, 45, v.23, n. 02, p. 54-67, 2을 semestre 2016. doi:

https://doi.org/10.12957/logos.2016.19601

ANDREEVA, G.; ANSELL, J.; HARRISON, T. Governance and accountability of public risk. Financial Accountability \& Management, v. 30, n. 3, p. 342-361, aug. 2014. doi: https://doi.org/10.1111/faam.12036

AVELINO, B. C.; ANGOTTI, M.; COLAUTO, R. D. Política de evidenciação de informações do setor público no estado de Minas Gerais. Revista Enfoque: Reflexão Contábil, Maringá, v. 31, n. 2, p. 47-61, mai./ago. 2012. doi: 10.4025/enfoque.v31i2.16079.

BAIRRAL, M. A. da C.; SILVA, A. H. C.; ALVES, F. J. dos S. Transparência no setor público: uma análise dos relatórios de gestão anuais de entidades públicas federais no ano de 2010. Revista de Administração Pública, Rio de Janeiro, v. 49, n. 3, p. 643-675, mai./jun. 2015. doi: https://doi.org/10.1590/0034-

7612125158

BARRETT, Pat. Achieving better practice corporate governance in the public sector. Australian National Audit Office, 2002.

BERNARDES, M. B.; SANTOS, P. M.; ROVER, A. J. Ranking das prefeituras da região sul do Brasil: uma avaliação a partir dos critérios estabelecidos na Lei de Acesso à Informação. Revista de Administração Pública, v. 49, n.3, p.761-792, maio/jun. 2015. doi: https://doi.org/10.1590/0034-7612119279

BEUREN, I. M.; SÖTHE, A. A Teoria da Legitimidade e o Custo Político nas evidenciações Contábeis dos Governos Estaduais da Região Sudeste do Brasil. Revista de Contabilidade e Organizações, v. 3, n. 5, p. 98-120, jan./abr. 2009. doi: https://doi.org/10.11606/rco.v3i5.34734

BEUREN, I. M.; GUBIANI, C. A.; SOARES, M. Estratégias de legitimidade de Suchman evidenciadas nos relatórios da administração de empresas públicas do setor elétrico. Revista Brasileira de Administração Pública, v.37, n.4, jul./ago. 2013. doi: https://doi.org/10.1590/S0034-76122013000400003

BOGONI, N. M.; ZONATTO, V. C. S.; ISHIKURA, E. R.; FERNANDES, F. C.. Proposta de um modelo de relatório de administração para o setor público baseado no Parecer de Orientação no 15/87 da Comissão de Valores Mobiliários: um instrumento de governança corporativa para a administração pública. Revista de Administração Pública, v. 44, n. 31, p. 119-142, jan./fev. 2010. doi: https://doi.org/10.1590/S003476122010000100006

BRASIL. Lei Complementar n. 101, de 04 de maio de 2000. Estabelece normas de finanças públicas voltadas para a responsabilidade na gestão fiscal e dá outras providências. Disponível em: http://www.planalto.gov.br. Acesso em: 18 de jan. 2017.

BRASIL. Lei Complementar n. 131, de 27 de maio de 2009. Acrescenta dispositivos à Lei Complementar no 101 , de 4 de maio de 2000 , que estabelece normas de finanças públicas voltadas para a responsabilidade na gestão fiscal e dá outras providências, a fim de determinar a disponibilização, em tempo real, de 
informações pormenorizadas sobre a execução orçamentária e financeira da União, dos Estados, do Distrito Federal e dos Municípios. Disponível em: http://www.planalto.gov.br. Acesso em: 18 de jan. 2017.

BRASIL. Lei Complementar no 156, de 28 de dezembro de 2016. Altera a Lei Complementar no 101, de 4 de maio de 2000. Disponível em: http://www.planalto.gov.br/ccivil_03/leis/LCP/Lcp156.htm. Acesso em 24 mai. 2017.

BRASIL. Lei n. 12.527, de 18 de novembro de 2011. Regula o acesso a informações previsto no inciso XXXIII do art. 5o, no inciso II do $\S 30$ do art. 37 e no $\S 20$ do art. 216 da Constituição Federal; altera a Lei no 8.112, de 11 de dezembro de 1990; revoga a Lei no 11.111, de 5 de maio de 2005, e dispositivos da Lei no 8.159, de 8 de janeiro de 1991; e dá outras providências. Disponível em: http://www.planalto.gov.br. Acesso em: 18 de jan. 2017.

BRASIL. Tribunal de Contas da União. Referencial básico de governança aplicável a órgãos e entidades da administração pública. Versão 2. Brasília: TCU, Secretaria de Planejamento, Governança e Gestão, 2014. Disponível em:

http://portal.tcu.gov.br/lumis/portal/file/fileDownload.jsp?inline=1\&fileld=8A8182A24F0A728E014F0B34D331 418D. Acesso em 06 abr. 2016.

CALVOSA, M. V. D.; SILVA, T. A.; KRAKAUER, P. V. C. Portais Eletrônicos Utilizados nos Municípios Fluminenses: Análise das Ações Inovadoras. Sociedade, Contabilidade e Gestão, v. 12, n. 2, p. 63-79, 2017.

CAVALCANTE, M. E. S.R. O discurso autonomista do Tocantins. Goiânia: UCG, 2003.

CHEN, C.; NESHKOVA, M. I The effect of fiscal transparency on corruption: A panel cross-country analysis. Public Administration, v. 98, ed. 1, special: 226-243, 2020, doi: 10.1111/padm.12620.

CRUZ, C. F.; SILVA, L. M.; SANTOS, R. Transparência da gestão fiscal: um estudo a partir dos portais eletrônicos dos maiores municípios do Estado do Rio de Janeiro. Revista Contabilidade, Gestão e Governança, Brasília, v. 12, n. 3, p. 102-115, set./dez. 2009

CRUZ, C. F.; FERREIRA, A. C. de S.; SILVA, L. M. da; MACEDO, M. Á. S. Transparência da gestão pública municipal: um estudo a partir dos portais eletrônicos dos maiores municípios brasileiros. Revista de Administração Pública, Rio de Janeiro, v. 46, n. 1, p. 153-176, jan./fev. 2012. doi: https://doi.org/10.1590/S0034-76122012000100008

CUCCINIELLO, M.; PORUMBESCU, G. A.; GRIMMELIKHUIJSEN, Stephan. 25 years of transparency research: Evidence and future directions. Public Administration Review, v. 77, n. 1, p. 32-44, 2017. doi: https://doi.org/10.1111/puar.12685

FIGUEIREDO, V. S.; GAZONI, R. L. Transparência nos Sites dos Municípios do Estado do Rio de Janeiro. Revista de Contabilidade \& Controladoria, Curitiba, v. 8, n. 2, p.130-143, mai./ago. 2016. doi: http://dx.doi.org/10.5380/rcc.v8i2.42996.

GESUELE, B.; METALLO, C.; LONGOBARDI, S. The Determinants of E-Disclosure Attitude: Empirical Evidences from Italian and Spanish Municipalities. International Journal of Public Administration, v.41, n.11, pp.921-934, 2018. doi:https://doi.org/10.1080/01900692.2017.1300917

GOMES, A.S. Transparência nos portais eletrônicos: análise das informações divulgadas pelos municípios mais populosos da região Sudeste do Brasil. 2015. Dissertação (Mestrado em Ciências Contábeis) - Fundação Instituto Capixaba de Pesquisa em Contabilidade, Economia e Finanças (FUCAPE), Vitória, 2015.

HILGERS, D.; PILLER, F. T. A government 2.0: fostering public sector rethinking by open innovation. Innovation Management, v. 1, n. 2, pp.1-8, 2011.

INSTITUTO BRASILEIRO DE GEOGRAFIA E ESTATÍSTICA (IBGE). IBGE: cidades@: Todas as cidades: TO. Disponível em: http://cidades.ibge.gov.br/xtras/uf.php?coduf=17. Acesso em: 21 mar. 2016.

JAHNS, F. T.; RAUPP, F. M. Transparência do Poder Executivo dos Estados Brasileiros. Revista Universo Contábil, v. 12, n. 3, p. 65-72, set. 2016. doi: https://doi:10.4270/ruc.2016321 
LAZZINI, S.; ZARONE, V. Network accountability and governance of local public groups: evidence from Italy's local governments. International Journal of Business, Accounting, \& Finance, v. 6, n. 1, p. 156170, winter. 2012.

LEITE FILHO, G. A.; VIEIRA COLARES, A. F.; FONSECA ANDRADE, I. C. Transparência da Gestão Fiscal Pública: um Estudo a Partir dos Portais Eletrônicos dos Maiores Municípios do Estado de Minas Gerais. Contabilidade Vista \& Revista, v. 26, n. 2, p. 114-136, 24 ago. 2015.

MARENGO, S. T.; DIEHL, C. A.. A possibilidade do controle social mediante o acesso a informações em sites dos municípios gaúchos. Contabilidade, Gestão e Governança, Brasília, v. 14, n. 3, p.120-133, set./dez. 2011

MARQUES, S. B. S. da S. Transparência nos pequenos municípios do Rio Grande do Sul: um estudo sobre a divulgação de indicadores da LRF e da LAl. 2014. Dissertação (Mestrado em Ciências Contábeis) Universidade do Vale do Rio dos Sinos (UNISINOS), São Leopoldo, 2014.

MENESES, A. F. Evidenciação das demonstrações contábeis: estudo sob a óptica do processo de convergência das Normas de Contabilidade aplicadas ao setor público. 2011. Dissertação (Mestrado em Administração e Controladoria) - Universidade Federal do Ceará (UFC), Fortaleza, 2011.

OLIVEIRA, A. G. de; PISA, B. J. IGovP: Índice de avaliação da governança pública: instrumento de planejamento do Estado e de controle social pelo cidadão. Revista de Administração Pública, Rio de Janeiro, v. 49, n. 5, p. 1263-1290, set./out. 2015. doi: https://doi.org/10.1590/0034-7612136179 .

PAPENFUB, U.; SCHAEFER, C. Improving public accountability by aligning reporting to organizational changes in public service provision - an empirical Internet study of all Austrian, German and Swiss towns and states from an agency-theory perspective. International Review of Administrative Sciences, v. 76, n. 3, pp. 555-576, 2010. doi: https://doi.org/10.1177/0020852310372451.

PAULA, T.A. Transparência fiscal no governo do estado do Maranhão. 2010. Dissertação (Mestrado em Administração) - Fundação Getúlio Vargas (FGV), Rio de Janeiro, 2010.

PIRES, A. M.; SCHERER, F. L.; SANTOS, M. B. dos; CARPES, A. de M. Transparência da gestão pública municipal: um estudo dos municípios de Santa Maria e Novo Hamburgo / RS. Revista Estudos do CEPE, Santa Cruz do Sul, n. 38, p.131-160, jul./dez. 2013.

PLATT NETO, O. A.; CRUZ, F. da; ENSSLIN, S. R.; ENSSLIN, L. Publicidade e transparência das contas públicas: obrigatoriedade e abrangência desses princípios na administração pública brasileira.

Contabilidade Vista \& Revista, Belo Horizonte, v. 18, n. 1, p.75-94, jan./mar. 2007.

https://www.redalyc.org/articulo.oa?id=197014728005.

RAUSCH, R,. B.; SOARES, M. Controle social na administração pública: a importância da transparência das contas públicas para inibir a corrupção. Revista de Educação e Pesquisa em Contabilidade, Brasília, v. 4, n. 3, p. 23-43, set./dez. 2010. doi: https://doi.org/10.17524/repec.v4i3.250.

RÍOS, A. M.; GUILLAMÓN, M. D.; BENITO, B.; BASTIDA, F. The influence of transparency on budget forecast deviations in municipal governments. Journal of Forecasting, v.37, pp. 457-474, 2018.

ROGOSIC, A.; PALOS, K. P. Public Sector Accounting: Transparency Issues. European Scientific Journal, v. 13, n. 10, pp. 13-23, 2017.

SANTOS, G. DOS; MOTA, F. P. B. A transparência governamental em tempos de COVID-19: reflexões do quadro brasileiro. Gestão e Sociedade, v. 14 n. 39, 2020: especial COVID-19, 2020. doi: https://doi.org/10.21171/ges.v14i39.3288

SAEZ-MARTIN, A.; CABA-PEREZ, C.; LOPEZ-HERNANDEZ, A. Freedom of information in local government: rhetoric or reality? Local Government Studies, v.43, n.2, pp.245-273, 2017. https://doi.org/10.1080/03003930.2016.1269757

SECCHI, L.. Modelos organizacionais e reformas da administração pública. Revista de Administração Pública, Rio de Janeiro, v. 43, n. 2, p. 347-369, mar./abr. 2009. https://doi.org/10.1590/S0034-

76122009000200004 
SILVA, A. L. Evidenciação de informações nas páginas web de prefeituras municipais matogrossenses: uma análise de aderência à Lei de Responsabilidade Fiscal e à Lei de Acesso à Informação. 2013. Dissertação (Mestrado em Ciências Contábeis) - Universidade do Vale do Rio dos Sinos (UNISINOS), São Leopoldo, 2013.

SILVA, D. J. M.; SEGATTO, J. A. C.; SILVA, M. A. Disclosure no serviço público: análise da aplicabilidade da lei de transparência em municípios mineiros. Revista Catarinense da Ciência Contábil, Florianópolis, v. 15, n. 44, p. 24-36, jan./abr. 2016. doi: https://dx.doi.org/10.16930/2237-7662rccc.v15n44p24-36

SILVA, F. A.; MARTINS, T. C. P. M.; CKAGNAZAROFF I. B. Redes organizacionais no contexto da governança pública: a experiência dos Tribunais de Contas do Brasil com o grupo de planejamento organizacional. Revista do Serviço Público, Brasília, v. 64, n. 2, p. 249-271, abr./jun. 2013.

SOL, A. del. The institutional, economic and social determinants of local government transparency. Journal of Economic Policy Reform, v.16, n.1, pp.90-107, 2013. doi:

https://doi.org/10.1080/17487870.2012.759422

SOUZA, A.; BOINA, T. M.; AVELAR, E. A.; GOMIDE, P. L. R. Evidenciação Contábil nos Municípios Mineiros: Atendimento ao Artigo 48 da Lei de Responsabilidade Fiscal. Revista Pensar Contábil, Rio de Janeiro, v. 10, n. 42, p. 36-43, out./dez. 2008.

STAROSCKY, E. A.; LYRIO, M. V. L.; LUNKES, R. J.; COLE, B. P.; NUNES, G. S. F. An analysis on the web portals of the municipalities comprising the Regional Development Bureau of Joinville (SC), based on a Multicriteria Decision Making Model. Public Administration Research, v. 4, n. 1, pp.24-37, 2015. doi:10.5539/par.v4n1p24.

STYLES, A. K.; TENNYSON, M. The accessibility of financial reporting of U.S. municipalities on the Internet. Journal of Public Budgeting, Accounting \& Financial Management, v. 19, n. 1, pp. 56-92, 2007. doi:10.1108/jpbafm-19-01-2007-b003

TAGESSON, T.; KLUGMAN, M.; EKSTRÖM, M. L. What explains the extent and content of social disclosures in Swedish municipalities' annual reports. Journal of Management \& Governance, v. 17, n. 2, p. 217-235, may. 2013. https://doi.org/10.1007/s10997-011-9174-5.

TAVARES, W.; CERQUINHO, K. G.; PAULA, A. P. P. Participação Virtual na Gestão Pública no Âmbito Municipal: Uma Análise dos Portais Eletrônicos das Capitais Brasileiras. Desenvolvimento em Questão, v. 16, n. 43, pp. 263-290, 2018. doi: http://dx.doi.org/10.21527/2237-6453.2018.43.263-290.

VISENTINI, M. S.; SANTOS, M. D. Transparência na Gestão Pública Municipal Evidenciada nos Portais Eletrônicos dos Municípios do Conselho Regional de Desenvolvimento (Corede) das Missões/RS. Desenvolvimento em Questão, v. 17, n. 49, p. 158-175, 2019. doi: http://dx.doi.org/10.21527/2237-6453.2019.49.158-175

WELCH, E.W. The relationship between transparent and participative government: a study of local governments in the United States. International Review of Administrative Sciences, v. 78, n. 1, pp. 93115, 2012. doi: https://doi.org/10.1177/0020852312437982.

\section{NOTAS}

\section{AGRADECIMENTOS}

Não se aplica.

\section{CONTRIBUIÇÃO DE AUTORIA}

Concepção e elaboração do manuscrito: X. M. B.Araújo, C. A. Kronbauer

Coleta de dados: X. M. B.Araújo

Análise de dados: C. A. Kronbauer, J. R. M. Carvalho, G. M. P. Cirne, X. M. B.Araújo

Discussão dos resultados: C. A. Kronbauer, J. R. M. Carvalho, G. M. P. Cirne

Revisão e aprovação: C. A. Kronbauer, J. R. M. Carvalho, G. M. P. Cirne

\section{CONJUNTO DE DADOS DE PESQUISA}

O conjunto de dados que dá suporte aos resultados deste estudo não está disponível publicamente.

\section{FINANCIAMENTO}

Não se aplica. 


\section{CONSENTIMENTO DE USO DE IMAGEM}

Não se aplica.

\section{APROVAÇÃO DE COMITÊ DE ÉTICA EM PESQUISA}

Não se aplica.

\section{CONFLITO DE INTERESSES}

Não se aplica.

\section{LICENÇA DE USO}

Os Direitos Autorais para artigos publicados neste periódico são do autor, com direitos de primeira publicação para a Revista. Em virtude de aparecerem nesta Revista de acesso público, os artigos são de uso gratuito, com atribuições próprias, em aplicações educacionais, de exercício profissional e para gestão pública. A Revista adotou a licença Creative Commons Atribuição 4.0 Internacional - CC BY NC ND. Esta licença permite acessar, baixar (download), copiar, imprimir, compartilhar, reutilizar e distribuir os artigos desde que com a citação da fonte, atribuindo os devidos créditos de autoria. Nesses casos, nenhuma permissão é necessária por parte dos autores ou dos editores. Autores têm autorização para assumir contratos adicionais separadamente, para distribuição não-exclusiva da versão do trabalho publicada nesta revista (ex.: publicar em repositório institucional ou um capítulo de livro).

\section{PUBLISHER}

Universidade Federal de Santa Catarina. Curso de Ciências Contábeis e Programa de Pós-graduação em Contabilidade. Publicação no Portal de Periódicos UFSC. As ideias expressadas neste artigo são de responsabilidade de seus autores, não representando, necessariamente, a opinião dos editores ou da universidade.

\section{EDITORES}

Carlos Eduardo Facin Lavarda e Suliani Rover

\section{HISTÓRICO}

Recebido em: 15/08/2019 - Revisado por pares em: 15/05/2020 - Reformulado em: 15/06/2020 Recomendado para publicação em: 10/07/2020 - Publicado em: 30/07/2020

Uma versão preprint deste artigo foi apresentada no XXVI Congresso Brasileiro de Custos, 2019

\footnotetext{
${ }^{\mathrm{i}}$ A estrutura completa do modelo com as respectivas tabelas dos indicadores encontra-se com os autores. Tais informações poderão ser disponibilizadas. Optou-se pela não inclusão em razão da limitação de espaço.
} 